\title{
Optimization of pervious concrete containing fly ash and iron oxide nanoparticles and its application for phosphorus removal
}

Natalia I. Vázquez-Rivera, Linoshka Soto-Pérez, Juliana N. St John, Omar I. Molina-Bas, Sangchul S. Hwang*

Department of Civil Engineering and Surveying, University of Puerto Rico, Mayagüez, PR 00681

* Corresponding author: sangchul.hwang@upr.edu, +1-787-265-3815

\begin{abstract}
Response surface methodology by a two-level central composite design optimized the ratios of water-to-binder (W/B), fly ash-to-binder (FA/B) and iron oxide nanoparticles-to-binder (ENP/B) for Portland cement pervious concrete (PCPC). Compressive strength, permeability, void content and density ranged 2.5-13.5 MPa, 5.3-17.4 mm/sec, 12-22\% and 2,120-2,360 kg/m $\mathrm{m}^{3}$, respectively. W/B and FA/B had significant impacts on all the PCPC properties, whereas ENP/B produced significance only for the compressive strength. PCPC was optimized with $0.35 \mathrm{~W} / \mathrm{B}, 0.15 \mathrm{FA} / \mathrm{B}$ and $0.05 \mathrm{ENP} / \mathrm{B}$. The optimized PCPC exhibited enhanced phosphorus removal with the first-order removal constant at $0.031 \mathrm{hr}^{-1}$ and the Freundlich isotherm constant at $2.48 \mathrm{mg}^{1-1 / n} \mathrm{~kg}^{-1} \mathrm{~L}^{1 / \mathrm{n}}$.

Key words: Compressive strength, Permeability, Phosphorus, Response Surface Methodology, Void content
\end{abstract}

(C) 2015. This manuscript version is made available under the Elsevier user license http://www.elsevier.com/open-access/userlicense/1.0/ 


\section{Introduction}

The use of Portland cement pervious concrete (PCPC) pavement is among the best management practices for the management of storm water runoff. PCPC pavement decreases the necessity of water detention ponds, permits groundwater recharge, decreases or eliminates pollutants from runoff, and improves water quality [1,2]. PCPC pavement is usually designed to have a void ratio of $15-35 \%$ and a permeability of $1.4-12.3 \mathrm{~mm} / \mathrm{s}$. It has a typical compressive strength ranging from 2.8 to $28 \mathrm{MPa}$, which limits its potential use in structural applications [3].

For the purpose of improving the mechanical strength, nano-sized $\mathrm{SiO}_{2}, \mathrm{Al}_{2} \mathrm{O}_{3}$ and $\mathrm{Fe}_{2} \mathrm{O}_{3}$ have been added to cement mortar [4-6]. In addition, partial substitution of Portland cement with fly ash (FA) has also been done to improve strength gain at later ages. FA typically reacts with calcium hydroxide to form a product that is similar, but denser than the C-S-H gel, consequently having a cementitious paste less permeable [7,8]. Furthermore, FA substitution has environmental benefits by reducing carbon dioxide emission in the production of Portland cement and by lessening the burdens of solid waste management [9].

Numerous studies have investigated the mechanical strength and hydrological properties of PCPC with Portland cement as a binding material. However, very few studies have reported on the effect of FA addition to the PCPC on the physic-mechanical properties and its water purification performance. For examples, slightly lower compressive strengths were obtained for the FA-added PCPC than the normal PCPC [10]. As for water purification, phosphorus removal by the PCPC was attributed to precipitation in the form of $\mathrm{Ca}$ or $\mathrm{Mg}$ phosphates but FA addition to the PCPC did not have any significant effect on effluent phosphorus levels [11]. Yet, no investigations have been performed with the PCPC containing both FA and nanomaterials for its physico-mechanical characteristics and water purification.

In this study, iron oxide nanoparticles coated with surfactants $\left(\mathrm{ENP}_{\mathrm{Fe}-\mathrm{surf}}\right)$ and $\mathrm{FA}$ were used as admixtures to improve the properties of the PCPC in terms of compressive strength and phosphorus 
removal potential. First, the PCPC specimens were prepared in a three-factor, two-level central composite design. Second, physico-mechanical and hydrological properties of the PCPC were tested. Third, the levels of each factor were optimized for desired requirements of the PCPC. Fourth, the optimization was validated for accuracy of the statistical design. Finally, the PCPC designed with the optimized ratios of the factors was assessed for its rate and capacity for removal of phosphorous in solution. To the authors' knowledge, this was the first of its kind studying the physico-mechanical and hydrological properties and water purification potential of the FA-added PCPC with iron-oxide nanoparticles as an admixture.

\section{Materials and methodology}

\subsection{Portland cement, fly ash, nanoparticles and aggregates}

The Portland cement used was the CEMEX Type IP and complies with ASTM C595. It has a specific gravity of 2.86. The FA was obtained from a local coal-fueled power plant (AES Puerto Rico) and had a specific gravity of 2.55. The chemical composition of the Portland cement and FA are shown in Table 1. It should be noted that the FA complies with the Class C FA for the most of the chemical characteristics, except for its $\mathrm{SO}_{3}$ content that is much higher than the maximum percentage (5\%) specified in ASTM C618.

Iron oxide nanoparticles coated with surfactant(s) $\left(\mathrm{ENP}_{\mathrm{Fe}-\text { surf }}\right.$, MSG W10) were obtained from the Ferrotec (Bedford, NH). $\mathrm{ENP}_{\mathrm{Fe}-\text { surf }}$ is composed of (in \% vol.) nominal 10-nm magnetite (2.8-3.5), proprietary surfactant(s) (2.0-4.0), and water (92.5-95.2). It had a density of $1.245 \mathrm{~g} / \mathrm{mL}$.

The coarse aggregates used were limestone gravels purchased from a local hardware store. They were sieved to collect the sizes passing through the $9.5-\mathrm{mm}$ sieve but retaining on the $4.75-\mathrm{mm}$ sieve. No fine aggregates were used in the current study.

\subsection{Response Surface Methodology (RSM)}


RSM was performed by a three-factor, two-level central composite design with the Minitab 17 software. The three factors were: water-to-binder ratio (W/B), FA-to-binder ratio (FA/B), and ENP $_{\text {Fe-surf }}{ }^{-}$ to-binder ratio (ENP/B). In this study, the binder is defined as the mix of Portland cement and FA. The mass ratio of coarse aggregates to binder was fixed at 4:1 for all mixture designs. Each mixture was designed to make three specimens: two for the compressive strength test in duplicate and one for the tests of permeability, void content and hardened density. The two W/B levels were 0.34 and 0.40 with the axial points of 0.321 and 0.419 . For FA/B, the levels were 0.10 and 0.40 with the axial points of 0.005 and 0.495. The levels of ENP/B were 0.03 and 0.05 with the axial points of 0.003 and 0.063 .

The mixtures were prepared in a mechanical mixer, transferred to cylindrical molds of $20 \mathrm{~cm}$ in length and $10 \mathrm{~cm}$ in diameter, and compacted with a rod in accordance to ASTM C 192. The responses of compressive strength, permeability, void content, and hardened density were measured after curing the PCPC specimens for 7 days in $\mathrm{Ca}(\mathrm{OH})_{2}$-saturated tap water. The PCPC specimens prepared with the optimum mix design were validated for their compressive strength, permeability, void content and hardened density to assess the accuracy of the RSM results. In addition, they were used for phosphorus removal.

\subsection{Testing of PCPC specimens}

The compressive strength was tested in accordance to ASTM C39. Neoprene pad caps were used to evenly distribute the load on the top and bottom parts of the specimen. The permeability was calculated by a constant head method modified from ASTM D 2434, where a constant water column was maintained while water infiltrated through the specimen. Using the water volume collected $\left(\mathrm{V}_{\mathrm{W}}\right)$ at a time $(\mathrm{t})$, the constant water head $(\Delta \mathrm{h})$, and the diameter (D) and the height (L) of the specimen, the permeability (in $\mathrm{mm} / \mathrm{s}$ ) was calculated using Eqn. 1:

$$
\text { Permeability }=\frac{4 \cdot V_{w} \cdot L}{\pi \cdot D^{2} \cdot \Delta h \cdot t}
$$


The measurements of void content $(\%)$ and hardened density $\left(\mathrm{kg} / \mathrm{m}^{3}\right)$ of the PCPC specimens were conducted in compliance with ASTM C1754. The Eqns. 2 and 3 were used to calculate void content and hardened density, respectively; where $\mathrm{M}_{\mathrm{od}}$ is the mass of the oven-dried specimen $\left(35^{\circ} \mathrm{C}\right), \mathrm{M}_{\mathrm{sw}}$ is the mass of the specimen submerged in water, $\rho_{\mathrm{w}}$ is the water density, $\mathrm{D}$ is the specimen diameter, $\mathrm{L}$ is the specimen height, and $\mathrm{V}$ is the specimen volume.

Void Content $=\left(1-\left(\frac{M_{o d}-M_{S w}}{\rho_{w} D^{2} L}\right)\right) \times 100 \%$

Density $=M_{o d} / V$

The specimens prepared by the optimum mix design were tested for iron leaching. As iron could be dissolved out of either Portland cement, FA, or $\mathrm{ENP}_{\mathrm{Fe}-\text { surf, }}$, three different control PCPC specimens were tested in parallel with the PCPC specimens made with the optimum mix design (Table 2). After 24 hours of curing in $\mathrm{Ca}(\mathrm{OH})_{2}$-saturated tap water, all the specimens $(5 \mathrm{~cm}$ in diameter and $10 \mathrm{~cm}$ in length) were demolded and two specimens from each group were placed in the reactor (2-L glass beaker) containing DI water. Aqueous iron concentration was measured by the HACH Method 8008 for $~$ two weeks. After aqueous sampling, the same volume of fresh DI water was replenished to make the water volume constant during the experiment.

\subsection{Phosphorus removal by PCPC}

The specimens made with the optimized PCPC design and three control specimens (Table 2) were tested for their rate and capacity for aqueous phosphorus removal. A kinetic experiment was first conducted to obtain an equilibrium time of phosphorus removal in contact with the PCPC, where two PCPC specimens $(5 \mathrm{~cm}$ in diameter and $10 \mathrm{~cm}$ in length each) were placed in a 2-L glass beaker

containing a phosphorus concentration at $10 \mathrm{mg} / \mathrm{L}$ as $\mathrm{PO}_{4}{ }^{3-}$. Aqueous phosphorus concentration was 
measured by the HACH Method 8190 at time intervals for 120 hours. The values of $\mathrm{pH}$ were also measured by submerging a $\mathrm{pH}$ probe in the aqueous solution.

For the isotherm study, two PCPC specimens $(5 \mathrm{~cm}$ in diameter and $10 \mathrm{~cm}$ in length each) were placed in a 2-L beaker that had the different initial phosphorus concentrations $(1,2.5,5,10,25$ and 50 $\left.\mathrm{mg} / \mathrm{L} \mathrm{PO}_{4}{ }^{3-}\right)$. After 72 hours of equilibrium time, which was determined from the kinetic study aforementioned, aqueous phosphorus concentration and $\mathrm{pH}$ were measured in the same manner as in the kinetic experiment.

\section{Results and discussion}

\subsection{Responses from the RSM}

The compressive strength was measured in a range of 2.5 to $13.5 \mathrm{MPa}$ with a median value at 9.6 MPa. These were lower than the reported values of 2.8 to 28 MPs [3] due most likely to a shorter curing time of 7 days. In general, FA-added concrete slowly gains the mechanical strength due to delayed earlyage hydration of FA-cement systems [12,13]. The permeability was measured between 5.3 and $17.4 \mathrm{~mm} / \mathrm{s}$ with a median value at $8.2 \mathrm{~mm} / \mathrm{s}$, whereas the void content between 10.8 and $22.2 \%$ (median: 14.7\%). These two parameters were in a good agreement with the reported ranges of permeability at 1.4-12.3 $\mathrm{mm} / \mathrm{s}$ and void content at 15-35\% (ACI, 2010). The hardened density ranged between 2,121 and 2,358 $\mathrm{kg} / \mathrm{m}^{3}$ (median: 2,281 kg/m $\mathrm{m}^{3}$ ). Sonebi and Bassuoni (2013) also reported a similar range of hardened density for 7-day cured PCPC specimens $\left(1,952-2,364 \mathrm{~kg} / \mathrm{m}^{3}\right)[14]$.

Using the testing results of the RSM, a matrix plot (Fig. 1) was developed and the Pearson's correlation coefficients, $r$, were derived (Table 3). It was observed that the compressive strength did not have a strong correlation with the other variables; however, it had a weak inverse correlation with the permeability and void content and a weak direct correlation with the hardened density. Permeability had a 
direct correlation with void content and an inverse correlation with hardened density. Void content and hardened density had an inverse correlation with each other. In other words, when the void content is higher, the greater chances of void interconnection would occur, resulting in a higher permeability. The correlations between the variables were generally in good agreement with the reported ones $[3,15]$.

Using a second-order statistical model (Eqn. 4), the regression models were estimated for each response:

$y=\beta_{0}+\beta_{i} x_{i}+\beta_{j} x_{j}+\beta_{k} x_{k}+\beta_{i} x_{i}^{2}+\beta_{j} x_{j}^{2}+\beta_{k} x_{k}^{2}+\beta_{i j} x_{i} x_{j}+\beta_{i k} x_{i} x_{k}+\beta_{j k} x_{j} x_{k}$

where, $y$ is the response, $\beta_{0}$ is the intercept coefficient, $\beta_{i}, \beta_{j}$ and $\beta_{k}$ the linear coefficients of the factors $x_{i}$, $x_{j}$ and $x_{k}$, respectively, $\beta_{i i}, \beta_{j j}$, and $\beta_{k k}$ the quadratic coefficients of the factors $x_{i}, x_{j}$ and $x_{k}$, respectively, and $\beta_{i j}, \beta_{i k}$, and $\beta_{j k}$ the interaction coefficients between the factors $x_{i}, x_{j}$ and $x_{k}$, respectively.

Estimated regression models for compressive strength, permeability, void content, and hardened density are given in Eqns. 5 - 8, where three independent variables W/B, FA/B, and ENP/B are in coded values. The models incorporated only those terms that were statistically relevant $(p<0.05)$. The $R^{2}$ values for compressive strength, permeability, void content and density of hardened concrete were 81.1, 80.9, 79.9 , and $73.9 \%$, respectively.

$$
\begin{aligned}
& \text { Compressive Strength }=9.47+1.16 \frac{W}{B}-2.01 \frac{F A}{B}+0.70 \frac{E N P}{B} \\
& \text { Permeability }=8.92-2.45 \frac{W}{B}-0.93 \frac{F A}{B}+0.96\left(\frac{W}{B}\right)^{2}-1.07 \frac{W}{B} \frac{F A}{B}+0.97 \frac{W}{B} \frac{E N P}{B}-0.90 \frac{F A}{B} \frac{E N P}{B} \\
& \text { Void Content }=14.94-2.31 \frac{W}{B}+0.85 \frac{F A}{B}+0.76\left(\frac{W}{B}\right)^{2} \\
& \text { Hardened Density }=2273.08+41.40 \frac{W}{B}-23.28 \frac{F A}{B}-20.58\left(\frac{W}{B}\right)^{2}
\end{aligned}
$$

\subsection{Contour plots from the RSM}


Contour plots were obtained for compressive strength, permeability, void content and hardened density of PCPC mixtures at the fixed ENP/B at 3 or $5 \%$ as it had the least effect on the responses among the factors. The results are shown in Figs. 2 and 3.

The compressive strength only had linear effects of the variables (Eqn. 5). The increase in W/B resulted in less increase in the compressive strength than the decrease in FA/B. The ENP/B also had a positive but the least effect on the compressive strength. The contour plots (Figs. 2a and 3a) graphically illustrate such positive influences of $\mathrm{W} / \mathrm{B}$ and $\mathrm{ENP} / \mathrm{B}$ and a negative influence of $\mathrm{FA} / \mathrm{B}$ on the compressive strength.

The permeability had linear and quadratic influence of $\mathrm{W} / \mathrm{B}$, a linear influence of $\mathrm{FA} / \mathrm{B}$ and interaction influences between the variables (Eqn. 6). The linear W/B had the greatest influence on the permeability followed by the interactions of (W/B)(FA/B) and (W/B)(ENP/B). As shown in Figs. 2b and $3 \mathrm{~b}$, the increases in W/B and FA/B decreased and increased the permeability, respectively. Excess water or a higher W/B could produce bleeding of the paste leading to a reduction in permeability. The increased FA/B might counteract the influence of W/B because FA generally reacts with more water due to smaller particle sizes and higher surface area, the resulting paste is in a less fluid state. It was also observed that the increase of ENP/B also decreased the permeability. As the $\mathrm{ENP}_{\mathrm{Fe} \text {-surf }}$ used in the current study was coated with proprietary surfactants, the permeability could be decreased due to excessive workability causing the paste to drip to the bottom (i.e., bleeding).

The W/B had the greatest influence on the void content with negative linear and positive quadratic effects. On the other hand, FA/B had only a positive linear influence (Eqn. 7). This implies that the void content generally increases with the decreased W/B but with the increased FA/B (Figs. 2c and 3c). The influences of the variables on the void contents were similar to those on the permeability. This was expected since the permeability and void contents were proportionally related with the Pearson's correlation coefficient of $(+) 0.90$ (Table 3$)$. 
The hardened densities were significantly affected by the W/B with linear and quadratic influences and the FA/B with a linear influence (Eqn. 8). Increasing the W/B had a greater influence on increasing the hardened densities than reducing the FA/B. Although the ENP/B did not significantly affect the hardened densities, Figs. 2d and 3d show its relatively marginal effect on the hardened density.

\subsection{PCPC optimization by overlaid contour plots}

Overlaid contour plots were established to obtain a combination of the factor levels that simultaneously satisfy all the desired optimum values for each response. The chosen ranges of the desired compressive strength, permeability, void content and hardened density were 10 to $13 \mathrm{MPa}, 8$ to $14 \mathrm{~mm} / \mathrm{s}$, 15 to $20 \%, 2,200$ to $2,300 \mathrm{~kg} / \mathrm{m}^{3}$, respectively.

The optimum region (in white) at a fixed ENP/B constant at 3\% (Fig. 4a) was narrower than that at 5\% (Fig. 4b). In addition, the optimum region was found in the lower W/B and higher FA/B ranges at a greater ENP/B. This implies that the increase of ENP/B is beneficial, as a lesser amount of water is needed for PCPC and as a greater amount of FA can replace the Portland cement while the PCPC satisfies the desired requirement for each response. The optimum mix design was chosen to be $0.34,0.15$ and 0.05 were chosen for W/B, FA/B and ENP/B ratios, respectively.

\subsection{Validation of the optimized PCPC}

The RSM optimization was validated for each response with the PCPC specimens prepared in duplicate by the aforementioned optimum mixture design. Table 4 shows the results of the compressive strength, permeability, void content and hardened density. The validation was satisfied for the void content, permeability and density, with the results falling into the desired optimum ranges. However, the compressive strength (8.8 MPa on average) was slightly lower than the low value of the desired optimum range (10 MPa).

\subsection{Iron Leaching from PCPC}


Aqueous iron concentrations were too low to measure or were below the detection limit of 0.02 $\mathrm{mg} / \mathrm{L}$ for two weeks of iron leaching experiment with the specimens shown in Table 2. It is noted that the iron leaching experiment was done with the specimens cured only for 24 hours. Therefore, it is construed that the added iron-oxide nanoparticles will not leach irons once the PCPC is cured for a longer period of time.

\subsection{Phosphorus Removal by PCPC}

Phosphorus (as $\mathrm{PO}_{4}{ }^{3-}$ ) removal rate was determined at a fixed initial phosphorus concentration at 10 mg $\mathrm{PO}_{4}{ }^{3-} / \mathrm{L}$. As shown in Fig. 5a as an example, phosphorus concentrations were exponentially decreased and $>90 \%$ removal was achieved after 72 hours of contact time. The PCPC specimens containing ENP $_{\mathrm{Fe}-}$ surf (i.e., the control 3 and the optimum specimens) had a slightly faster first-order removal constant $(k)$ of $0.031 \mathrm{hr}^{-1}$ than the other two specimens that had $\mathrm{k}=0.028 \mathrm{hr}^{-1}$ (Table 5). Aqueous $\mathrm{pH}$ was between 7.6 and 8.2 for the first one hour, was increased to $\sim 12$ after 24 hours and was maintained at $\sim 12$ until the end of the experiment (120 hrs).

For the isotherm study, batch reactors were run for the 72-hr equilibrium time with six different phosphorus concentrations for each specimen type. The isotherm data were fitted by the Freundlich equation (Eqn. 9) as shown in Fig. 5b as an example.

$$
q_{e}=K_{f} \cdot C_{e}^{1 / n}
$$

where, $\mathrm{q}_{\mathrm{e}}$ is the removed phosphorus amount at equilibrium $(\mathrm{mg} / \mathrm{kg}), \mathrm{C}_{\mathrm{e}}$ is the aqueous phosphorus

concentration at equilibrium $(\mathrm{mg} / \mathrm{L}), \mathrm{K}_{\mathrm{f}}$ is the Freundlich constant $\left(\mathrm{mg}^{1-1 / \mathrm{n}} \mathrm{kg}^{-1} \mathrm{~L}^{1 / \mathrm{n}}\right)$, and $1 / \mathrm{n}$ is a dimensionless parameter.

Table 5 also contains $\mathrm{K}_{\mathrm{f}}, 1 / \mathrm{n}$ and $\mathrm{R}^{2}$ values of the Freundlich equation. The optimum PCPC specimens had the greatest $K_{f}$ value of all. Since the unit of $K_{f}$ depends on the value of $1 / n$, $K_{f}$ 's are only comparable when their $1 / \mathrm{n}$ values are the same. As the values of $1 / \mathrm{n}$ in this study were very similar 
ranging from 1.54 to 1.7 , it can be said that the optimal PCPC had the greatest phosphorous removal capacity judged by its greatest $\mathrm{K}_{\mathrm{f}}$ value of all.

Phosphorus removal can be attributed to precipitation in the forms of hydroxyapatite $\left(\mathrm{Ca}_{10}\left(\mathrm{PO}_{4}\right)_{6}(\mathrm{OH})_{2}\right)$ and amorphous calcium phosphate $\left(\mathrm{Ca}_{3}\left(\mathrm{PO}_{4}\right)_{2}\right)[16,17]$. In the current study, $\mathrm{Ca}^{2+}$ ions leached out of the PCPC would be responsible for phosphorus precipitation. In fact, a more precipitation that was assumed to be hydroxyapatite/calcium phosphate was visually noticed on the bottom of the reactors at a higher initial phosphorus concentration.

\section{Conclusions}

The following conclusions can be derived from the current study:

- Compressive strength, permeability, void content and hardened density of the PCPC specimens ranged 2.5-13.5 $\mathrm{MPa}, 5.3-17.4 \mathrm{~mm} / \mathrm{sec}, 12-22 \%$ and $2,120-2,360 \mathrm{~kg} / \mathrm{m}^{3}$, respectively, from the RSM performed by a three-factor, two-level central composite design with the ratios of W/B, FA/B and ENP/B being 0.34-0.40, 0.1-0.4 and 0.03-0.05, respectively.

- The increase in FA/B resulted in the most decrease in the compressive strength of PCPC, whereas the ENP/B had a positive but the least effect on the compressive strength. The void content generally increased with the decreased W/B but with the increased FA/B.

- The optimum PCPC mix design was determined at $0.34 \mathrm{~W} / \mathrm{B}, 0.15 \mathrm{FA} / \mathrm{B}$ and $0.05 \mathrm{ENP} / \mathrm{B}$, based on the optimization with overlaid contour plots to obtain a combination of the factor levels that simultaneously satisfied the desired optimum values for each response.

- The optimum PCPC specimens were able to remove aqueous phosphorus at a first-order removal constant, $k$, of $0.031 \mathrm{hr}^{-1}$ and the Freundlich constants, $\mathrm{K}_{\mathrm{f}}$ of $2.48\left(\mathrm{mg}^{1-1 / \mathrm{n}} \mathrm{kg}^{-1} \mathrm{~L}^{1 / \mathrm{n}}\right)$ and $1 / \mathrm{n}$ of 1.7 . 


\section{Acknowledgments}

This research was made possible with financial support, in part, by AES Puerto Rico, LLC, the National Science Foundation (DMR-0934115), and the Puerto Rico NASA Space Grant Scholarship to Linoshka Soto-Pérez.

\section{References}

[1] Lian C, Zhuge Y. Optimum mix design of enhanced permeable concrete - An experimental investigation. Constr Build Mater 2010;24(12):2664-2671.

[2] Scholz M, Grabowiecki P. Review of permeable pavement systems. Build Environ 2007;42:38303836.

[3] ACI, American Concrete Institute Committee 522. Report on Pervious Concrete. 1st ed., ACI 522R10. American Concrete Institute, Michigan; 2010.

[4] Oltulu M, Sahin R. Effect of nano-SiO 2 , nano- $\mathrm{Al}_{2} \mathrm{O}_{3}$, nano- $\mathrm{Fe}_{2} \mathrm{O}_{3}$ powders on compressive strength and capillary water absorption of cement mortar containing fly ash: A comparative study. Energ Buildings 2013;58:292-301.

[5] Sanchez F, Sobolev K. Nanotechnology in concrete - A review. Constr Build Mater 2010;24:20602071.

[6] Singh LP, Karade SR, Bhattacharyya SK, Yousuf MM, Ahalawat S. Beneficial role of nanosilica in cement based materials. Constr Build Mater 2013;47:1069-1077.

[7] Deschner F, Winnefeld F, Lothenbach B, Seufert S, Schwesig P, Dittrich S, Goetz-Neunhoeffer F, Neubauer J. Hydration of Portland cement with high replacement by siliceous fly ash. Cem Concr Res 2012;42(10):1389-1400. 
[8] Uysal M, Akyuncu V. Durability performance of concrete incorporating Class F and Class C fly ashes. Constr Build Mater 2012;34:170-178.

[9] Blissett RS, Rowson NA. A review of the multi-component utilisation of coal fly ash. Fuel 2012;97:123.

[10] Tho-in T, Sata V, Chindaprasirt P, Jaturapitakkul C. Pervious high-calcium fly ash geopolymer concrete. Constr Build Mater 2012;30:366-371.

[11] Luck JD, Workman SR, Coyne MS, Higgins SF. Solid material retention and nutrient reduction properties of pervious concrete mixtures. Biosyst Eng; 2008;100:401-408.

[12] Chindaprasirt P, Jaturapitakkul C, Sinsiri T. Effect of fly ash fineness on microstructure of blended cement paste. Constr Build Mater 2007;21:1534-1541.

[13] Sakai E, Miyaharab S, Ohsawa S, Lee S, Daimon M. Hydration of fly ash cement. Cem Concr Res 2005;35(6):1135-1140.

[14] Sonebi M, Bassouni MT. Investigating the effect of mixture design parameters on pervious concrete by statistical modeling. Constr Build Mater 2013;38:147-154.

[15] Ibrahim A, Mahmoud E, Yamin M, Patibandla VC. Experimental study on Portland cement pervious concrete mechanical and hydrological properties. Constr Build Mater 2014;50:524-529.

[16] Okano K, Uemoto M, Kagami J, Miura K, Aketo T, Toda M, Honda K, Ohtake H. Novel technique for phosphorus recovery from aqueous solutions using amorphous calcium silicate hydrates (ACSHs). Water Res 2013;47:2251-2259.

[17] Wang X, Chen J, Kong Y, Shi X. Sequestration of phosphorus from wastewater by cement-based or alternative cementitious materials. Water Res 2014;62:88-96. 

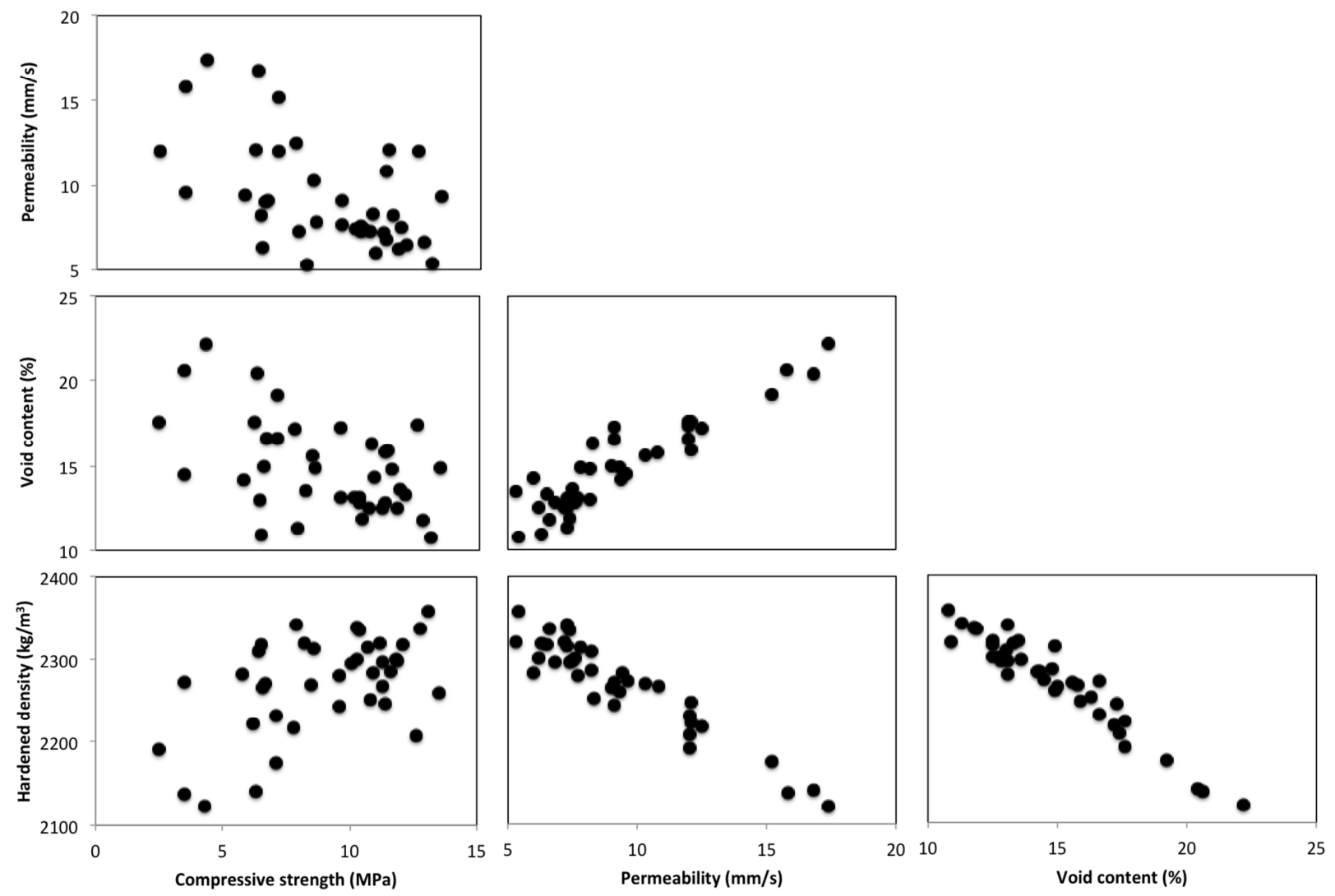

Fig. 1. Matrix plot between the responses of compressive strength, permeability, void content and hardened density of PCPC. 

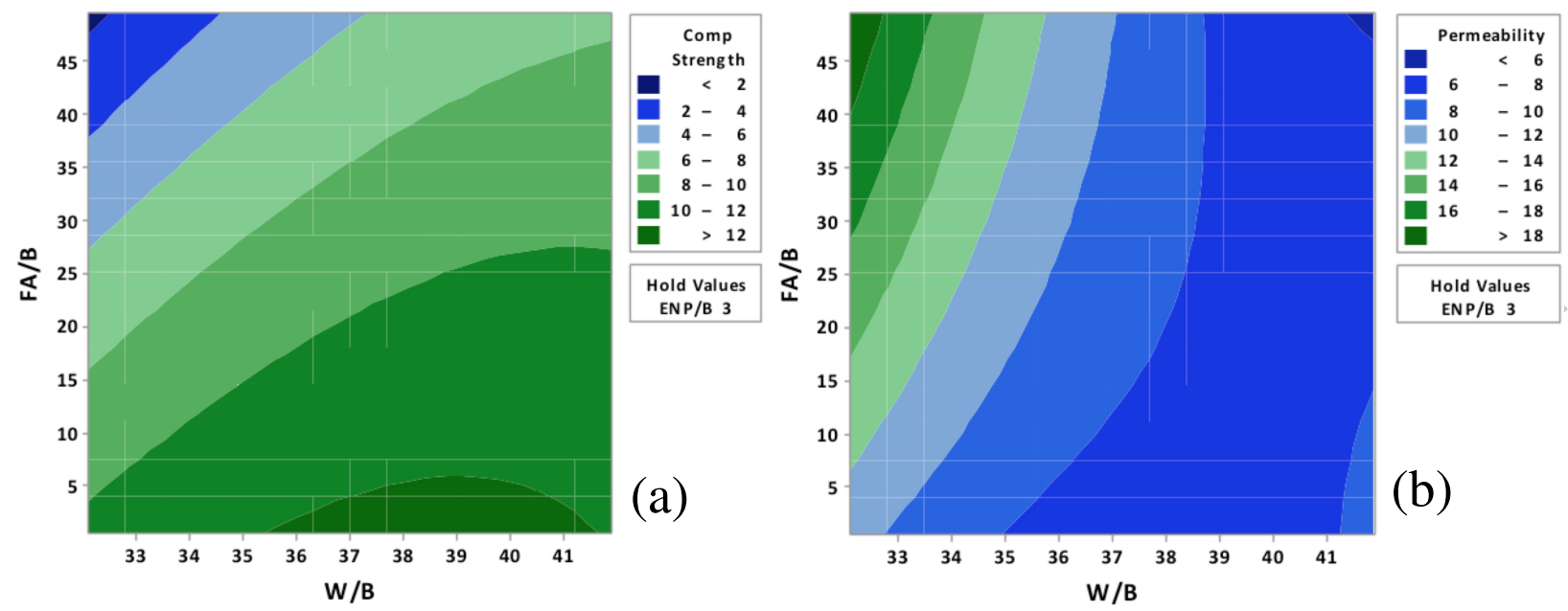

(a) ENP/B 3
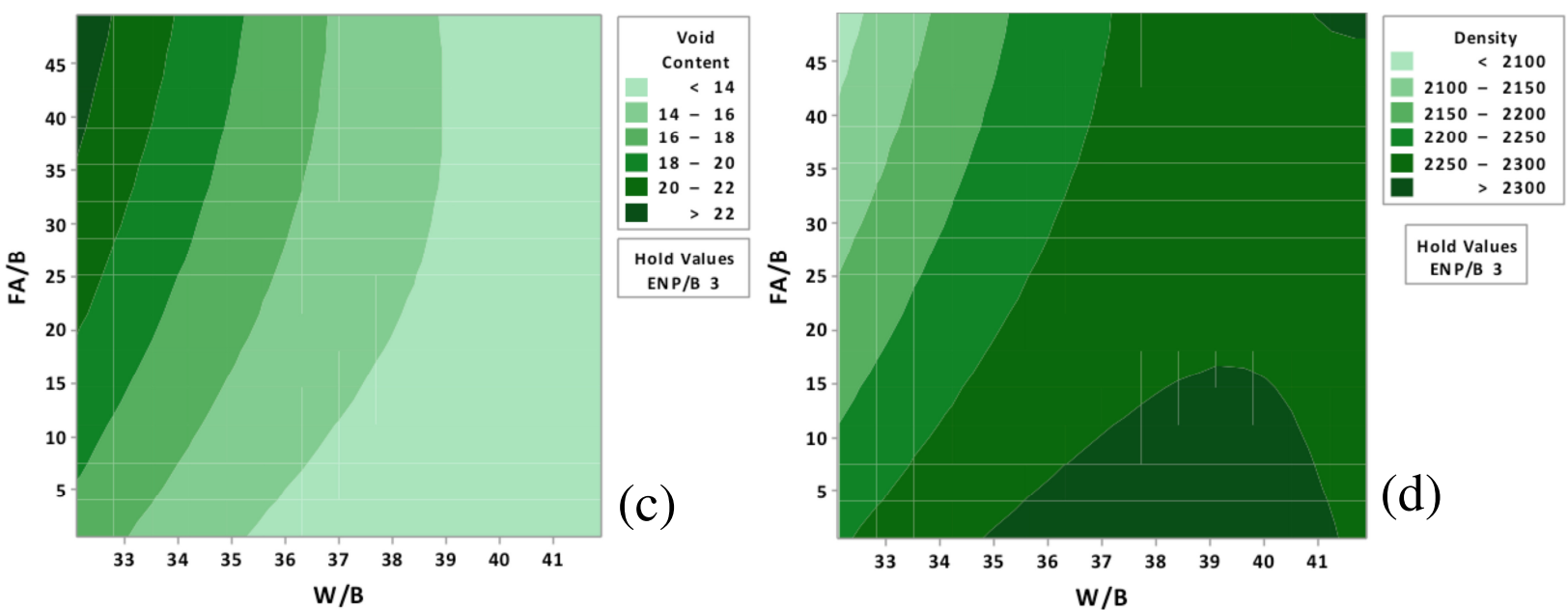

Fig. 2. Contour plots for compressive strength (MPa) (a), permeability (mm/s) (b), void content (\%) (c), and hardened density $\left(\mathrm{Kg} / \mathrm{m}^{3}\right)(\mathrm{d})$ in a function of FA/B $(\%)$ and W/B (\%) while ENP/B held at 3\%. 

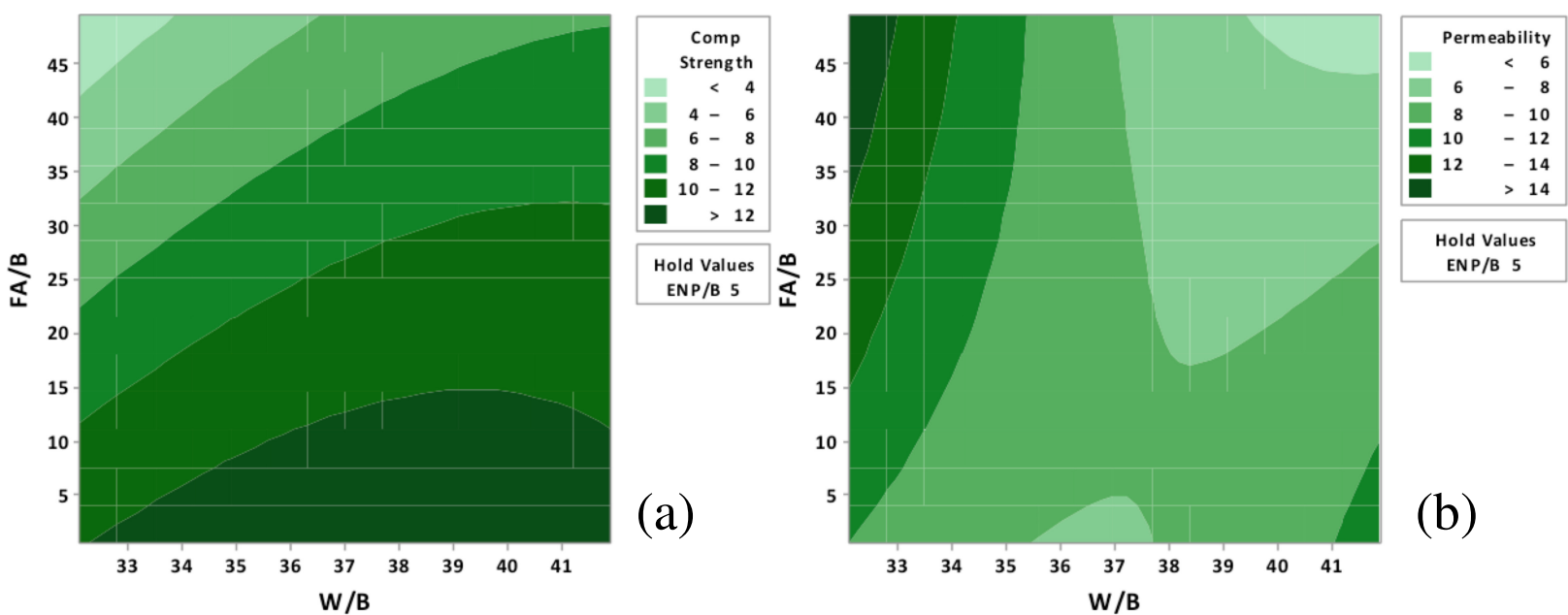

(a)
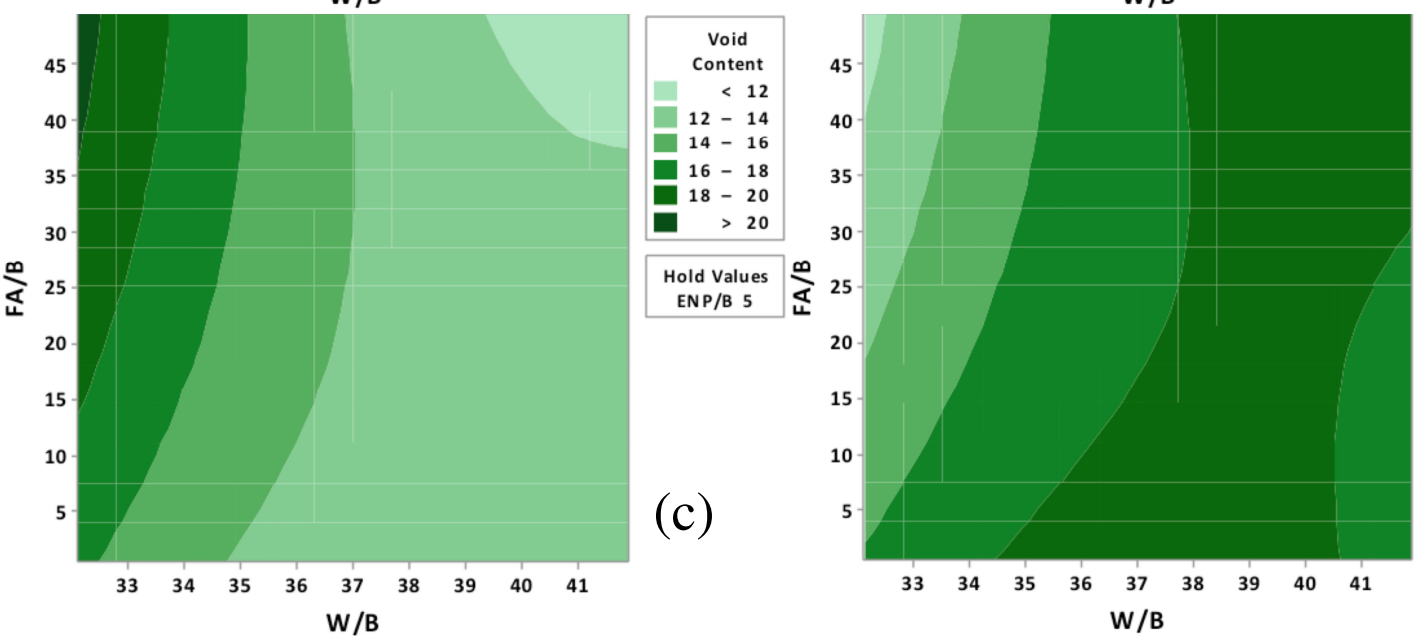

(b)

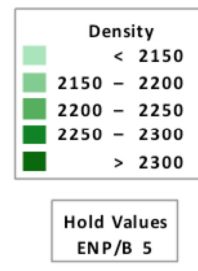

Fig. 3. Contour plots for compressive strength (MPa) (a), permeability $(\mathrm{mm} / \mathrm{s})(\mathrm{b})$, void content (\%) (c), and hardened density $\left(\mathrm{Kg} / \mathrm{m}^{3}\right)(\mathrm{d})$ in a function of FA/B (\%) and W/B (\%) while ENP/B held at 5\%. 
(a)

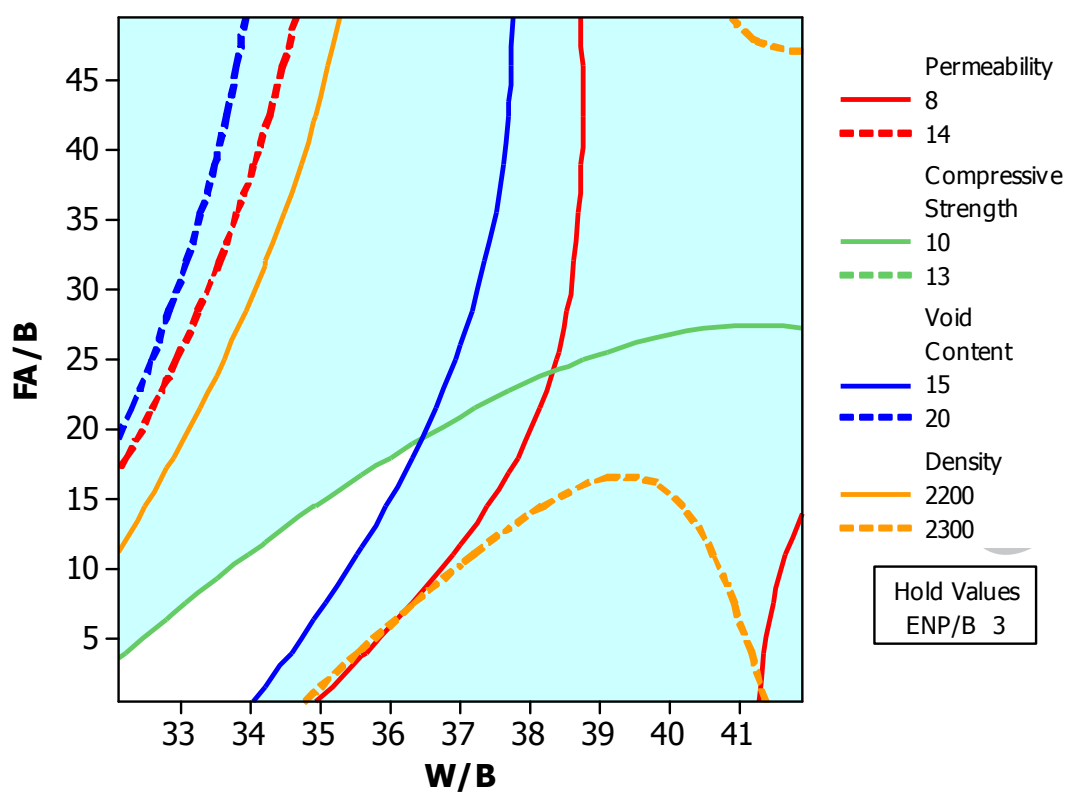

(b)

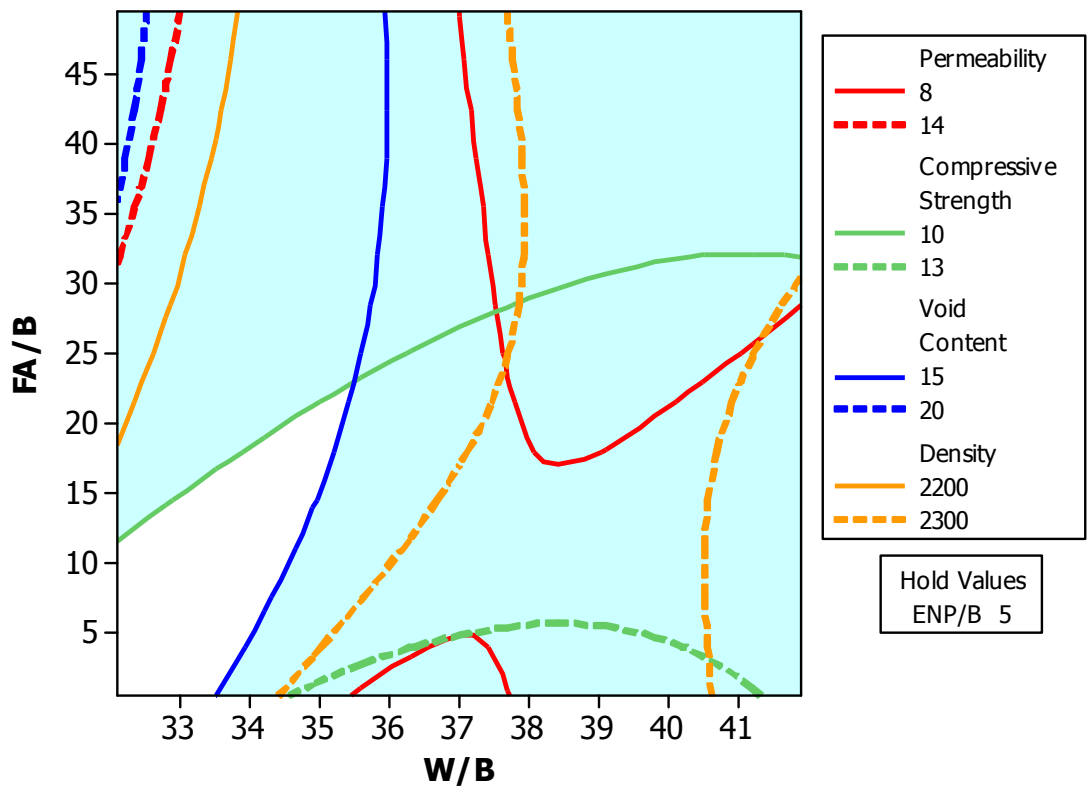

Fig. 4. Overlaid contour plots for compressive strength (MPa), permeability $(\mathrm{mm} / \mathrm{s})$, void content (\%), and density $\left(\mathrm{Kg} / \mathrm{m}^{3}\right)$ of hardened concrete in a function of $\mathrm{FA} / \mathrm{B}(\%)$ and W/B $(\%)$ while ENP/B held at $3 \%$ (a) and $5 \%$ (b). 

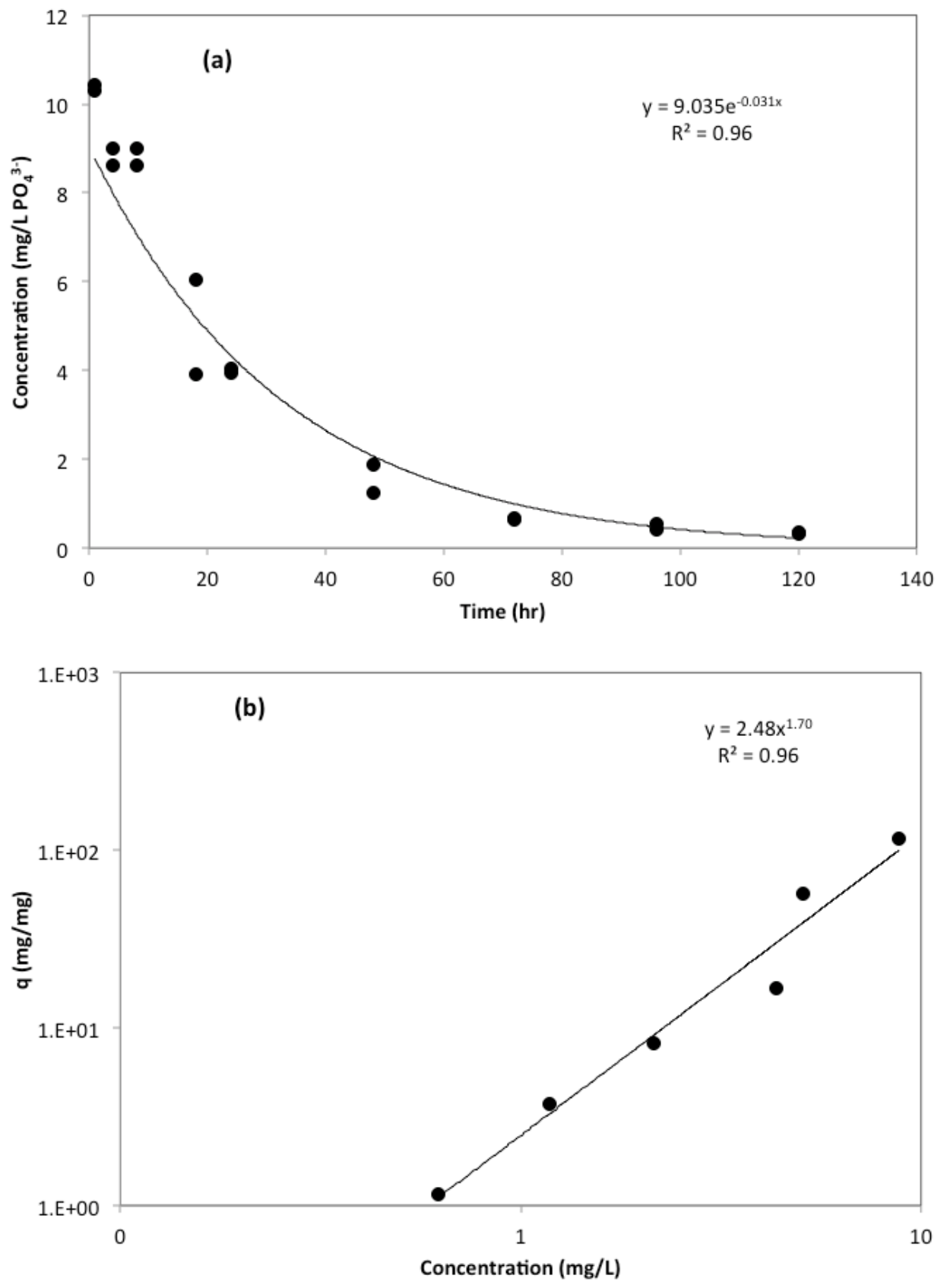

Fig. 5. Kinetic results (a) and the Freundlich isotherm (b) of aqueous phosphorus reduction by the optimum PCPC. 


\section{Table 1}

Chemical composition of Portland cement (PC) and fly ash (FA).

\begin{tabular}{llllllllllll}
\hline \multicolumn{10}{c}{ Oxide content (wt. \%) } \\
& $\mathrm{SiO}_{2}$ & $\mathrm{Al}_{2} \mathrm{O}_{3}$ & $\mathrm{Fe}_{2} \mathrm{O}_{3}$ & $\mathrm{CaO}$ & $\mathrm{MgO}$ & $\mathrm{SO}_{3}$ & $\mathrm{Na}_{2} \mathrm{O}$ & $\mathrm{K}_{2} \mathrm{O}$ & $\mathrm{TiO}_{2}$ & $\mathrm{P}_{2} \mathrm{O}_{5}$ \\
\hline PC & 27.14 & 6.68 & 3.71 & 55.47 & 1.62 & 3.48 & 0.59 & 0.48 & 0.32 & 0.11 \\
FA & 30.84 & 9.93 & 5.01 & 39.61 & 0.35 & 11.43 & 0.90 & 1.01 & 0.45 & 0.11 \\
\hline
\end{tabular}


Table 2

PCPC specimens for assessment of iron leaching and phosphorus removal.

\begin{tabular}{cccc}
\hline PCPC & \multicolumn{3}{c}{ Ratios } \\
& W/B & FA/B & ENP/B \\
\hline Control 1 & 0.34 & 0 & 0 \\
Control 2 & 0.34 & 0.15 & 0 \\
Control 3 & 0.34 & 0 & 0.05 \\
Optimum & 0.34 & 0.15 & 0.05 \\
\hline
\end{tabular}


Table 3

Pearson's correlation coefficients (r values) for each response ${ }^{a}$.

\begin{tabular}{lccc}
\hline & Compressive Strength (Mpa) & Permeability $(\mathrm{mm} / \mathrm{s})$ & Void Content (\%) \\
\hline Permeability $(\mathrm{mm} / \mathrm{s})$ & -0.548 & & \\
Void Content $(\%)$ & -0.490 & -0.90 & -0.92 \\
Density $\left(\mathrm{kg} / \mathrm{m}^{3}\right)$ & 0.537 & & \\
\hline${ }^{\mathrm{a}}$ r-value indicates the strength and direction of the correlation.
\end{tabular}


Table 4

Validation results of the optimum PCPC for compressive strength, permeability, void content and hardened density.

\begin{tabular}{lcc}
\hline \multicolumn{1}{c}{ Response } & Desired optimum range & Validation results in duplicate \\
\hline Compressive strength $(\mathrm{MPa})$ & $10-13$ & $8.0,9.5$ \\
Permeability $(\mathrm{mm} / \mathrm{s})$ & $8-14$ & $11.0,12.9$ \\
Void content $(\%)$ & $15-20$ & $16.2,17.9$ \\
Hardened density $\left(\mathrm{kg} / \mathrm{m}^{3}\right)$ & $2,200-2,300$ & $2,245,2,286$ \\
\hline
\end{tabular}


Table 5

First-order phosphorus removal constant $\left(\mathrm{k}, \mathrm{hr}^{-1}\right)$ from the kinetic study and the Freundlich constant $\left(\mathrm{K}_{\mathrm{f}}\right.$, $\left.\mathrm{mg}^{1-1 / \mathrm{n}} \mathrm{kg}^{-1} \mathrm{~L}^{1 / \mathrm{n}}\right)$ with the dimensionless Freundlich constant $(1 / \mathrm{n})$ from the isotherm study.

\begin{tabular}{lcccccc}
\hline \multirow{2}{*}{ PCPC } & \multicolumn{2}{c}{ Kinetic study } & & \multicolumn{3}{c}{ Freundlich isotherm } \\
\cline { 2 - 3 } \cline { 5 - 6 } & $\mathrm{k}$ & $\mathrm{R}^{2}$ & & $\mathrm{~K}_{\mathrm{f}}$ & $1 / \mathrm{n}$ & $\mathrm{R}^{2}$ \\
\hline Control 1 & 0.028 & 0.95 & & 2.32 & 1.56 & 0.96 \\
Control 2 & 0.028 & 0.94 & & 2.22 & 1.6 & 0.92 \\
Control 3 & 0.031 & 0.97 & & 1.97 & 1.54 & 0.98 \\
Optimum & 0.031 & 0.96 & & 2.48 & 1.7 & 0.96 \\
\hline
\end{tabular}

